\title{
Association of the nicotinic receptor $\alpha 7$ subunit gene (CHRNA7) with schizophrenia and visual backward masking
}

\section{George Bakanidze ${ }^{1 *}$, Maya Roinishvili ${ }^{2,3}$, Eka Chkonia ${ }^{3,4}$, Werner Kitzrow ${ }^{1}$, Sarina Richter ${ }^{1}$, Konrad Neumann ${ }^{5}$, Michael H. Herzog ${ }^{6}$, Andreas Brand ${ }^{7}$ and Imke Puls ${ }^{1}$}

\author{
'Genetic Section, Department of Psychiatry and Psychotherapy, CCM, Charité University Medicine, Berlin, Germany \\ 2 Department of Behaviour and Cognitive Functions, I. Beritashvili Institute of Physiology, Tbilisi, Georgia \\ ${ }^{3}$ Institute of Cognitive Neurosciences, Agricultural University of Georgia, Tbilisi, Georgia \\ ${ }^{4}$ Department of Psychiatry, Tbilisi State Medical University, Tbilisi, Georgia \\ ${ }^{5}$ Institute of Biometry and Clinical Epidemiology, CCM, Charite University, Berlin, Germany \\ ${ }^{6}$ Laboratory of Psychophysics, Brain Mind Institute, Ecole Polytechnique Fédérale de Lausanne (EPFL), Lausanne, Switzerland \\ ${ }^{7}$ Center for Psychiatry and Psychotherapy, Klinikum Bremen-Ost, Bremen, Germany
}

\section{Edited by:}

Filippo Drago, University of Catania, Italy

\section{Reviewed by:}

Ju Wang, University of Virginia, USA

Emilio Clementi, University of Milano, Italy

\section{*Correspondence:}

George Bakanidze, Psychiatrische Universitätsklinik der Charite, im St. Hedwig-Krankenhaus, Psychiatrische Institutsambulanz, Große Hamburge Straße 5-11, 10115 Berlin, Germany e-mail: george.bakanidze@charite.de
The nicotinic system is involved in the pathophysiology of schizophrenia. However, very little is known about its genetic basis and how it relates to clinical symptoms and potentially pharmacological intervention. Here, we investigated five single nucleotide polymorphisms (SNPs) [rs3826029] [rs2337506] [rs982574] [rs904952] [rs2337980] of the cholinergic nicotinic receptor gene, alpha 7 subunit (CHRNA7) and their association to schizophrenia. We found an association with rs904952 $(p=0.009)$ in a German sample of 224 schizophrenic patients and 224 healthy control subjects. The same trend was shown in an independent Georgian sample of 50 schizophrenic patients, 57 first order unaffected relatives, and 51 healthy controls. In addition, visual backward masking (VBM), a sensitive test for early visual information processing, was assessed in the Georgian sample. In line with prior studies, VBM performance deficits were much more pronounced in schizophrenic patients and their unaffected relatives compared to healthy controls (schizophrenic patients: $156 \mathrm{~ms}$; unaffected relatives: $60 \mathrm{~ms}$; healthy controls: $33 \mathrm{~ms}$ ). VBM was strongly correlated with SNP rs904952 $(H[2]=7.3, p=0.026)$. Our results further support the notion that changes in the nicotinic system are involved in schizophrenia and open the avenue for pharmacological intervention.

Keywords: endophenotypes, verniers, visual masking, genetics of schizophrenia, CHRNA7, nicotinic receptor

\section{INTRODUCTION}

Schizophrenia is a severe disease affecting patients' professional and social life. Schizophrenia is strongly influenced by genetic factors. A large variety of candidate genes have been identified in the last years with controversial results (1-4). A major reason for the contradicting findings is the large number of genetic and environmental factors contributing to the pathophysiology of schizophrenia (5).

The nicotinic system has been found to play an important role in the pathogenesis of schizophrenia (6-8). Evidence for a relationship between the cholinergic nicotinic receptor alpha 7 subunit (CHRNA7) and schizophrenia was shown by both association (911) and linkage studies (12-14), although with mixed results (5, 15). A deletion of $15 \mathrm{q} 13.3$, the chromosomal location of CHRNA7, was identified in schizophrenic patients (16-18) together with deficiencies in cholinergic transcription in the corpus callosum (7) and reductions of the receptor protein in the hippocampus, cortex, and thalamus $(6,19,20)$. Schizophrenic patients are often heavy smokers, which may be a way of self medication (21-24). Although several lines of evidence point to the nicotinic system, current drugs applied in schizophrenic patients largely neglected this system.
Visual information processing is disturbed in schizophrenic patients. For example, sensorimotor gating has been found to be impaired in schizophrenic (25) and bipolar patients with psychotic mania (26). Visual backward masking (VBM) and particularly the shine-through masking paradigm are reliable methods of measuring deficits of visual processing (27-31). The shine-through paradigm showed impaired masking in schizophrenic patients and their first-degree relatives (27) compared to healthy controls. Because of this and other findings, the shine-through masking paradigm is a potential endophenotype of schizophrenia (27). We have recently argued that these deficits are not of primary visual nature but are related to deficient mechanisms of target enhancement (32). Neural activity of low contrast or briefly presented elements needs to be enhanced to counteract overwriting of subsequently presented stimuli. We postulated that the cholinergic system is one candidate of target enhancement which may be deficient in schizophrenic patients (32). These observations are in line with other studies which showed that the nicotinic system is involved in the regulation of visual information processing (33-36) including sensory gating and P50 suppression $(9,37)$. Interestingly, an alpha 7 receptor agonist improved both p50 gating function and cognition in schizophrenic patients (38). The 
cholinergic nicotinic receptor alpha 4 subunit gene (CHRNA4) has been found to modulate both auditory and visual information processing (39). For this reason, we targeted the cholinergic system and determined the influence of five single nucleotide polymorphisms (SNPs) on the diagnosis of schizophrenia in a German sample of 224 schizophrenic patients and 224 healthy controls. We further investigated these effects in a smaller Georgian sample with 50 schizophrenic patients, 57 first-degree unaffected relatives, and 51 healthy controls and determined VBM in addition. The SNPs where selected according to ABI SNP browser selection ${ }^{1}$.

\section{METHODS}

\section{PARTICIPANTS}

Data were collected from a German sample of 224 schizophrenic patients and 224 healthy controls. All subjects were of Central European descent. Group characteristics are depicted in Table 1. The diagnosis of schizophrenia was made according to DSM-IV criteria. Severity of psychopathology was assessed by an experienced clinician (I. Puls) using the Positive and Negative Symptom Scale (PANSS), the Scale for the Assessment of Positive Symptoms (SAPS), and the Scale for the Assessment of Negative Symptoms (SANS) (40, 41). Patients were on various neuroleptic agents, including haloperidol, olanzapine, risperidone, amisulpride, quetiapine, aripiprazole, ziprasidone. Individuals with present or life time alcohol and/or drug dependency as well as other psychiatric and neurological diseases were excluded from the study. All patients were recruited at the Department of Psychiatry and Psychotherapy, Charité, in Berlin, Germany. For comparison, 224 healthy controls were recruited from the general population. All controls were free of any axis 1 and 2 or major somatic disorders.

For evaluation of VBM, we repeated the experiment in a Georgian sample including 50 schizophrenic patients, 57 first order relatives, and 51 healthy control subjects. All subjects were of Central European descent recruited at the Asatiani Psychiatric Institute in Tbilisi, Georgia. The diagnosis of schizophrenia was made according to DSM-IV criteria. Psychopathology was assessed using SANS and SAPS by an experienced clinician (27). Individuals with alcohol and/or drug dependency, as well as other diseases that could affect the mental state of the subject were excluded from

${ }^{1}$ http://marketing.appliedbiosystems.com/mk/get/snpb_landing the study. All relatives and controls were free of any axis 1 and 2 disorder, which was confirmed by the Schizotypal Personality Questionnaire (SPQ).

\section{PROCEDURE}

The study was approved by the local ethic committees in Berlin and Tbilisi and was performed in accordance with the Declaration of Helsinki (1964). Approvals were obtained from the Georgian National Council on Bioethics (Meeting Statement of Ethical Committee of Institute of Postgraduate Medical Education and Continuous professional Development $\mathrm{N}$ 9/07) and the ethics committee of the University Hospital Charite, Berlin (Ethikkommission, Ethikausschuss 1 Campus Charite - Mitte, application number: EA1/115/10). All participants gave informed written consent prior to their participation. All participants received a clinical interview, evaluating the present medical state, and prior diseases. In schizophrenic patients, the degree of psychopathology was assessed. In all study participants, $30 \mathrm{ml}$ of whole blood was taken for genetic analysis.

In the Georgian sample, visual acuity was determined by the Freiburg Visual Acuity Test (FrACT) for each eye separately. A value of at least 0.8 for at least one eye was required. Afterward, the shine-through masking paradigm was performed.

\section{THE SHINE-THROUGH BACKWARD MASKING PARADIGM}

The shine-through backward masking paradigm was performed in the Georgian sample only. Subjects observed the stimuli from a distance of $3.5 \mathrm{~m}$ in a room illuminated dimly by a background light (around $0.5 \mathrm{~lx})$. A pixel of the screen $\left(19^{\prime \prime}\right)$ comprised about $18^{\prime \prime}$ (arc sec) at this distance. Stimuli were white on a black background. Stimulus luminance was $100 \mathrm{~cd} / \mathrm{m}^{2}$. Refresh rate of the screen was $100 \mathrm{~Hz}$. Conditions were tested in blocks of 80 trials.

\section{Vernier}

A vertical vernier is composed of two vertical bars which are slightly offset either to the left or right. The length of a bar was $10^{\prime}$ (arc min). The bars were separated by a small gap of $1^{\prime}$. Thus, altogether a vernier was about $21^{\prime}$ long. In each trial, the vernier offset direction was chosen randomly. In a binary task, observers were asked to indicate this offset direction (left/right). Errors were indicated by an auditory signal.

Table 1 | Demographics.

\begin{tabular}{|c|c|c|c|c|c|c|c|}
\hline Variable & \multicolumn{3}{|c|}{ German sample } & \multicolumn{4}{|c|}{ Georgian sample } \\
\hline Male (\%) & 50.7 & 58.0 & $2.3(0.13)$ & 76 & 45.6 & 60.8 & $10.3(0.006)$ \\
\hline Age (mean) & 37.0 & 40.8 & $3.33(0.07)$ & 34 & 35 & 34 & $0.16(0.8)$ \\
\hline Education in years (mean) & - & - & - & 13 & 14 & 16 & $7.5(0.001)$ \\
\hline
\end{tabular}

${ }^{a}$ For categorical data (gender), Chi-square statistics are reported. For visual acuity, age, and education F statistic is shown. In study participants from Germany, only basic clinical and psychiatric information was assessed, whereas the Georgian sample was characterized in more detail. 


FD - Vernier Duration
ISI - Interstimulus Interval
SD - Grating Duration
FIGURE 1 I Shine-through paradigm. (A) A vernier comprised two vertical
bars which were slightly offset to the left (not shown) or right (shown here).
Observers indicated this offset direction. For each observer, we determined
the individual vernier duration (VD) for which 75\% correct responses were
reached. (B) In the next step, this individual vernier duration was used for
each observer. The vernier offset was fixed at 71" (arc sec). This vernier was
followed by a blank screen (ISI) and a grating comprised of 25 aligned
verniers, i.e., verniers without offset. SOA =VD + ISI.

\section{Vernier duration}

First, we tested unmasked verniers, i.e., without a grating. We aimed to find the shortest VD, for which observers could perform vernier offset discrimination reliably (43) (Figure 1A). For a given VD, we determined adaptively (44) whether offset discrimination was below 40" (arc sec). We started with VDs of $150 \mathrm{~ms}$ and reduced durations blockwise until offset discrimination was above $40^{\prime \prime}$. Observers with VDs longer than $100 \mathrm{~ms}$ were excluded at this stage to ensure that all observers were rather "good" performers (sensitivity should not be boosted by bad "performers").

\section{Masking}

In the masking experiment, we presented the vernier with the individual duration for each observer. Vernier offset size was set to $71^{\prime \prime}$. First, an inter-stimulus interval (ISI) followed the vernier, and then, a masking grating (Figure 1B). The grating comprised 25 aligned verniers, i.e., without offset, of the same length and width as the target vernier. The horizontal distance between grating elements was about $3.33^{\prime}$. The vernier and the central element of the grating appeared always in the middle of the screen. The grating lasted for $300 \mathrm{~ms}$. We adaptively assessed the target-mask stimulus onset asynchrony (SOA) to yield a performance level of $75 \%$ correct responses for the vernier $(\mathrm{SOA}=\mathrm{VD}+\mathrm{ISI})$. In this part of the experiment, we varied the ISI, not the vernier offset size. The adaptive strategy started with an SOA of $200 \mathrm{~ms}$ that was either decreased or increased to find the individual threshold. A value of $450 \mathrm{~ms}$ was recorded if observers were unable to reach $75 \%$ correct responses for an SOA of $400 \mathrm{~ms}$ (45). We did not measure accuracy for different SOAs as it was done in most other masking studies in schizophrenia research, but we determined performance in one block.

\section{GENETIC ANALYSIS}

For genetic analysis, approximately $30 \mathrm{ml}$ EDTA blood samples were collected from each participant in both study cohorts. Genetic analysis for both chorts was performed in the Genetic
Table 2 | Single nucleotide polymorphisms genotyped within the CHRNA7 gene.

\begin{tabular}{llllll}
\hline $\begin{array}{l}\text { CHRNA7 } \\
\text { SNPs }\end{array}$ & Position & MAF & Alleles & Location & Reference \\
\hline rs3826029 & 3112042 & 0.409 & A/G & 5'near gene & Iwata et al. (42) \\
rs2337506 & 3136624 & 0.455 & G/A & Intron 2 & Iwata et al. (42) \\
rs982574 & 3164580 & 0.215 & G/C & Intron 2 & Iwata et al. (42) \\
rs904952 & 3209302 & 0.382 & $\mathrm{C} / \mathrm{T}$ & Intron 4 & Iwata et al. (42) \\
rs2337980 & 3234753 & 0.416 & T/C & Intron 4 & Iwata et al. (42) \\
\end{tabular}

The characteristics of SNPS are derived from the NCBI database. Contig position indicates the exact position of each SNP at contig NT_010194.16/17. MAF (minor allele frequency) is derived from 1000 Genome phase 1 genotype data from 1094 worldwide individuals, released in the May 2011 dataset. The minor allele is depicted in the first position. Location indicates the SNP position within the CHRNA7 gene.

Section, Department of Psychiatry and Psychotherapy, CCM, Charité University Medicine, Berlin. From the blood samples, DNA was extracted using standard procedures. Five SNPs of the cholinergic nicotine receptor gene, alpha 7 subunit (CHRNA7) were genotyped in the German and Georgian samples (for SNP details see Table 2). All SNPs have tagging function selected in consideration of both genetic and physical coverage that was based on Applied Biosystems SNPbrowser ${ }^{\mathrm{TM}}$ Software v3.5. Information about physical location and heterozygosity index of SNPs was derived from the University of California Santa Cruz (UCSC) Human Genome Browser ${ }^{2}$ and the National Center of Biotechnology Information (NCBI) SNP database ${ }^{3}$. Primers were designed for amplification of relevant DNA regions by polymerase chain reaction (PCR). PCR products were cut by allele specific restriction enzymes and visualized after gel electrophoresis (for PCR details see Table 3). Quality control was performed by in-gel standards to confirm expected fragments sizes and by random duplication of control samples for each plate. Primer information and specific assay conditions are available on request. Interpretation of gel electrophoresis was done by two independent investigators.

\section{STATISTICAL ANALYSIS}

For statistical analysis, SPSS v. 16.0 was used. We measured the association of genotype and diagnosis on both samples. In the Georgian sample, we additionally measured the SOA differences between the groups and the differences of SOA's between the carriers of different genotypes. To test for a relationship between categorical variables, such as allele variants (three categories) and study groups (three categories: patients, relatives, and controls), a crosstabulation analysis using Chi-square statistics was applied. For the analysis of categorical data such as gender, the Chi-square test was used. For quantitative, normally distributed data, $F$ statistics was used. For quantitative, non-normally distributed data [like shine-through data (SOA)] Kruskal-Wallis and Mann-Whitney tests were used. The power analysis was conducted using software

\footnotetext{
${ }^{2}$ http://www.genome.ucsc.edu/cgi-bin/hgGateway

${ }^{3}$ http://www.ncbi.nlm.nih.gov/sites/entrez
} 
Table 3 | Amplification and restriction details of SNPs studied.

\begin{tabular}{|c|c|c|c|c|c|c|c|c|c|}
\hline \multirow[t]{2}{*}{ CHRNA7 SNPs } & \multirow[t]{2}{*}{ Genotype } & \multirow[t]{2}{*}{ Forward primer } & \multirow[t]{2}{*}{ Reverse primer } & \multirow[t]{2}{*}{ Product size } & \multirow[t]{2}{*}{ Restriction products } & \multirow[t]{2}{*}{ Enzyme } & \multirow[t]{2}{*}{$t^{\circ}$} & \multicolumn{2}{|c|}{ GFR in \% } \\
\hline & & & & & & & & $\mathrm{DE}$ & GEO \\
\hline rs2337506 & $\mathrm{G} / \mathrm{A}$ & gccttggagtcacagctc & gcaatttcctactcctcgtc & 255 & $255,170,85$ & BssSI & 56 & 0.4 & 0 \\
\hline rs982574 & $\mathrm{G} / \mathrm{C}$ & cataacttagaatactcaacaag & gttgccaccacatctaccttc & 164 & $164,86,78$ & $M n / l$ & 56 & 0.9 & 0.6 \\
\hline rs904952 & $\mathrm{C} / \mathrm{T}$ & caaattggttaatttctgttcctAg & ccatggaaaacaggatgagtg & 134 & 134, 109, 25 & Alul & 56 & 0 & 0 \\
\hline
\end{tabular}

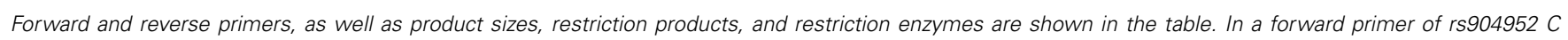

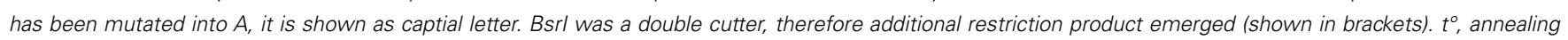
temperature; GFR, genotyping fail rate; DE, German sample; GEO, Georgian sample.

Table 4 | Hardy-Weinberg equilibrium in German and Georgian samples.

\begin{tabular}{llll}
\hline SNP & Genotype & \multicolumn{2}{c}{ HWE $\boldsymbol{p}$-value } \\
\cline { 3 - 4 } & & German & Georgian \\
\hline rs3826029 & A/G & 0.578 & 0.377 \\
rs2337506 & G/A & 0.899 & 0.946 \\
rs982574 & G/C & 0.146 & 1.0 \\
rs904952 & C/T & 0.005 & 0.632 \\
rs2337980 & T/C & 0.566 & 0.513 \\
\end{tabular}

$\mathrm{G}^{\star}$ Power version 3.1.3 (46). We expected an effect size of approximately 0.3 (Cramer's V). A sample size of $n=448$ is sufficiently large to detect an effect size of 0.3 (Cramer's V) with a power larger than $80 \%(1$-beta $=0.858)$ assuming alpha $=0.01$. HardyWeinberg equilibrium (HWE) and linkage disequilibrium (LD) were calculated with Haploview version $4.2(47,48)$. Details on HWE, as well as allele and genotype frequencies for each sample are given in Tables 4, 5, and 6. Details on LD are depicted in Figures 2A,B. Tagging SNPs were defined by Applied Biosystems SNPbrowser ${ }^{\mathrm{TM}}$ Software v3.5.

\section{RESULTS}

\section{DEMOGRAPHICS}

In the German sample, age $(p=0.069)$ and gender $(p=0.129)$ did not differ significantly between controls and patients. In the Georgian sample, groups also did not differ significantly for age $(F[2,155]=0.168 ; p=0.8)$. But gender $\left[\chi^{2}(2)=10.3 ; p=0.006\right]$ and education $(F[2,155]=7.5 ; p=0.001)$ were significantly different in the Georgian sample, with fewer females in the patient group and patients having poorer education compared to controls (Table 1). However the difference between males and females on VBM performance did not differ significantly $(U=208.5$, $p=0.66)$.

\section{CHRNA7 AND THE DIAGNOSIS OF SCHIZOPHRENIA}

In the German sample, we found an association of CHRNA7 with the diagnosis of schizophrenia. In SNP rs904952, the T allele was more frequently expressed in schizophrenic patients compared to controls $\left[\chi^{2}(1)=6.37 ; p=0.009\right]$ (Table 6). The $p$-value remained significant after Bonferroni correction for five SNPs $(0.05 / 5=0.01)$. In the Georgian sample, a relation between genetic variants in the CHRNA7 gene and the diagnosis of schizophrenia was found. In all of the five SNPs, including rs904952 and rs2337980 located in intron 4 of the CHRNA7 gene, the distribution of at least one allelic variant showed a pattern were relatives lie in between of patients and controls. The differences between the groups, however, did not reach significance likely because of the small sample size (Table 6; Figures 3A-E).

\section{STIMULUS ONSET ASYNCHRONY}

In line with previous studies $(9,27)$, we found significant differences in visual masking between patients, their first order relatives, and controls in the Georgian sample with the longest SOA for schizophrenic patients $(156 \mathrm{~ms})$, followed by the unaffected relatives $(60 \mathrm{~ms})$, and controls $(33 \mathrm{~ms})(\mathrm{H}[2]=68.3$, $p<0.0001$; Figure 4). Within the patient group, there was no significant difference between subjects taking the anticholinergic agent trihexyphenidyl and those who did not. Effects of other neuroleptic drugs have not been evaluated because of small sizes.

\section{CHRNA7 AND SOA}

In the Georgian sample, we found an association of the CHRNA7 gene with SOA level, with again the T allele of rs904952 as the risk variant. In the patient group, a significant effect of rs904952 on the SOA was found $(\mathrm{H}[2]=7.3, p=0.026$; Figure 5). Patients with the T/T genotype performed significantly worse than carriers of $\mathrm{C} / \mathrm{T}$ and $\mathrm{C} / \mathrm{C}$. We used the Mann-Whitney test to calculate the difference between the VBM performance of T/T and C/C carriers. The difference was statistically significant $(U=5, p=0.021)$ with an effect size of $r=-0.48$. No such effect was observed in healthy relatives or controls. Furthermore, no significant influence of any other SNP on the SOA was found.

\section{DISCUSSION}

We found an association of the cholinergic nicotinic receptor gene alpha 7 subunit (CHRNA7) with schizophrenia. Particularly one SNP (rs904952) in intron 4 seems to be important: T allele carriers were more often among schizophrenic patients compared to healthy controls in the German sample. Similar results were found in the Georgian sample but data did not reach significance, 
Table 5 | Genotype frequencies in German and Georgian samples.

\begin{tabular}{|c|c|c|c|c|c|c|c|c|c|c|c|c|c|c|c|}
\hline & \multicolumn{3}{|c|}{ rs3826029 } & \multicolumn{3}{|c|}{ rs2337506 } & \multicolumn{3}{|c|}{ rs982574 } & \multicolumn{3}{|c|}{ rs904952 } & \multicolumn{3}{|c|}{ rs2337980 } \\
\hline & A/A & A/G & G/G & G/G & G/A & A/A & $\mathbf{G} / \mathbf{G}$ & $\mathbf{G} / \mathbf{C}$ & $\mathrm{C} / \mathrm{C}$ & $\mathrm{C} / \mathrm{C}$ & $\mathrm{C} / \mathrm{T}$ & $\mathrm{T} / \mathrm{T}$ & $T / T$ & $\mathrm{~T} / \mathrm{C}$ & $\mathrm{C} / \mathrm{C}$ \\
\hline \multicolumn{16}{|c|}{ GEORGIAN } \\
\hline Whole & 0.089 & 0.361 & 0.551 & 0.449 & 0.437 & 0.114 & 0.025 & 0.266 & 0.703 & 0.127 & 0.494 & 0.380 & 0.367 & 0.500 & 0.127 \\
\hline Patients & 0.040 & 0.360 & 0.600 & 0.480 & 0.460 & 0.060 & 0.060 & 0.240 & 0.700 & 0.060 & 0.560 & 0.380 & 0.480 & 0.400 & 0.120 \\
\hline Relatives & 0.070 & 0.421 & 0.509 & 0.456 & 0.439 & 0.105 & 0.018 & 0.246 & 0.719 & 0.088 & 0.491 & 0.421 & 0.351 & 0.474 & 0.175 \\
\hline Controls & 0.157 & 0.294 & 0.549 & 0.412 & 0.412 & 0.176 & 0 & 0.314 & 0.686 & 0.235 & 0.431 & 0.333 & 0.275 & 0.627 & 0.078 \\
\hline \multicolumn{16}{|c|}{ GERMAN } \\
\hline Whole & 0.025 & 0.295 & 0.676 & 0.563 & 0.375 & 0.058 & 0.040 & 0.210 & 0.777 & 0.201 & 0.567 & 0.232 & 0.225 & 0.513 & 0.259 \\
\hline Patients & 0.022 & 0.317 & 0.661 & 0.558 & 0.393 & 0.049 & 0.040 & 0.246 & 0.741 & 0.152 & 0.638 & 0.210 & 0.210 & 0.554 & 0.237 \\
\hline Controls & 0.027 & 0.272 & 0.692 & 0.567 & 0.357 & 0.067 & 0.040 & 0.174 & 0.813 & 0.250 & 0.496 & 0.254 & 0.241 & 0.473 & 0.281 \\
\hline
\end{tabular}

Genotype frequencies for each SNP in both samples and in each group of these sample.

Table 6 | Association of CHRNA7 with diagnosis in German and Georgian samples.

\begin{tabular}{|c|c|c|c|c|c|c|c|c|c|c|}
\hline & Minor/major & \multicolumn{3}{|c|}{ Georgian sample } & $x^{2}$ & $p$-Value & \multicolumn{2}{|c|}{$\begin{array}{c}\text { German sample } \\
\text { MAF }\end{array}$} & $\chi^{2}$ & $p$-Value \\
\hline rs3826029 & $\mathrm{A} / \mathrm{G}$ & 0.220 & 0.281 & 0.304 & 5.84 & 0.212 & 0.181 & 0.164 & 1 & 0.606 \\
\hline rs2337506 & $\mathrm{G} / \mathrm{A}$ & 0.290 & 0.325 & 0.382 & 3.47 & 0.482 & 0.246 & 0.248 & 1 & 0.606 \\
\hline rs2337980 & $\mathrm{T} / \mathrm{C}$ & 0.320 & 0.412 & 0.400 & 7.74 & 0.101 & 0.487 & 0.477 & 2.75 & 0.252 \\
\hline
\end{tabular}

Association of CHRNA7 polymorphisms with the diagnosis in German and Georgian samples. Showing the genotype with minor allele in the first position, MAF, minor allele frequencies; $\chi^{2}$, Chi-square value; $p$, significance.

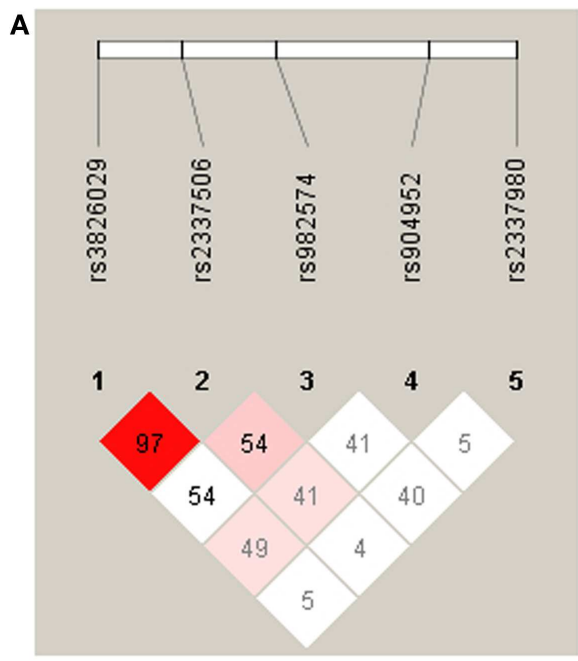

FIGURE 2 | Linkage disequilibrium analysis in German (A) and

Georgian (B) samples. The strength of LD is determined as Lewontin's $D^{\prime}$. In the German sample the SNPs rs3826029 and rs2337506 showed
B

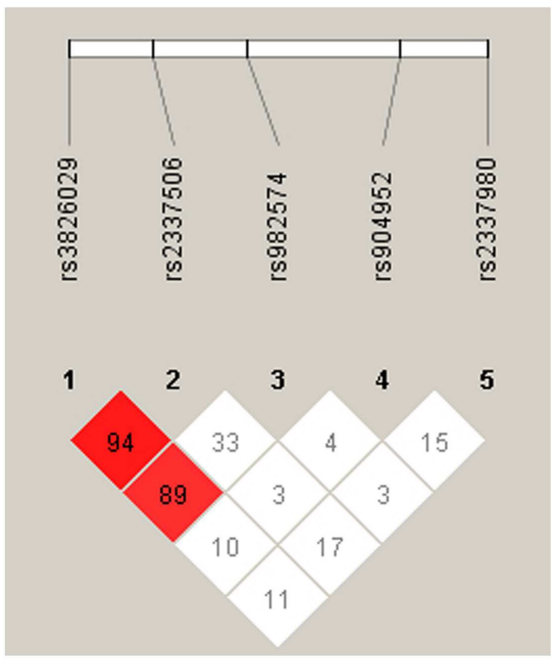

high linkage with $D^{\prime}$ of 0.97 . In the Georgian sample, rs3826029 and rs2337506 with $D^{\prime} 0.94$ and rs3826029 and rs982574 with $D^{\prime}$ of 0.89 were in high linkage disequilibrium. probably due to the small sample size. Gault et al. (49) showed that six different CHRNA7 transcripts are generated in the human brain by alternative splicing of exons 3 through 5 . This could be at least partly directed by sequence variations in intron 4, explaining the major effect of the genetic variations in our study. Our results further support the significance of the nicotinic system as 

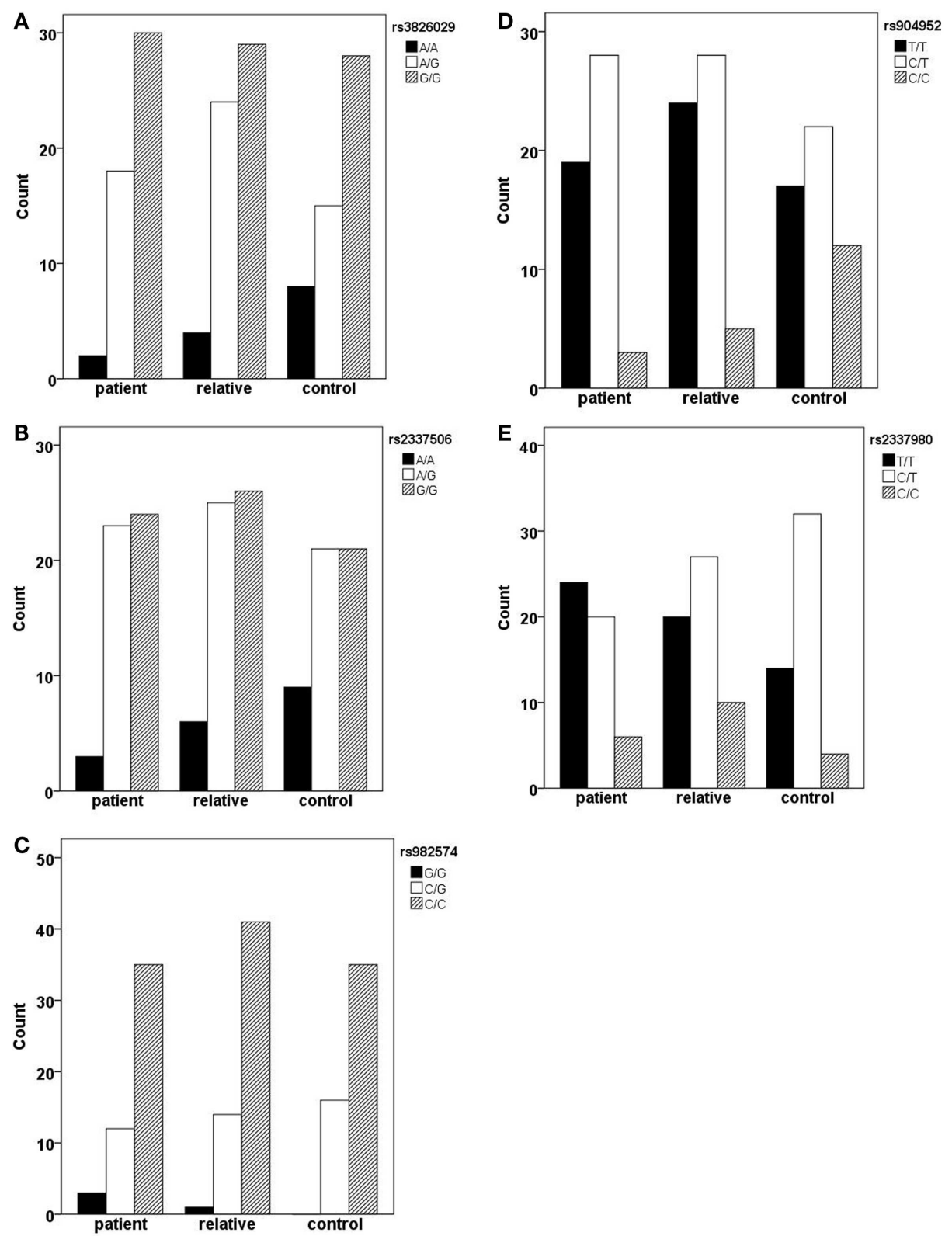

FIGURE 3 | Allelic variants of the five SNPs (rs3826029 (A), rs904952 (B), rs2337506 (C), rs2337980 (D), rs982574 (E)) of patients,

first-order relatives, and healthy controls. In all of the five SNPS, for

at least one allelic variant the count for relatives is in between patients and controls. However, the differences between groups are not statistically significant.

an important pathway in schizophrenia which may be the target for pharmacological intervention.

Our findings are in line with the majority of prior studies in this field. Case-control (9-11) and family (13, 14, 50-53) studies found a positive relationship between polymorphisms in the CHRNA7 gene and schizophrenia. Most of these studies investigated microsatellites as genetic markers. At the moment of conducting the present study, there were no SNPs reported to be associated with schizophrenia. Later Stephens et al. (11) and Stephens et al. (54) found three SNPs, which were significantly

associated witch diagnosis of schizophrenia. Fan et al. (55) conducted both case-control as well as family studies in a Chinese population and found no relationship between schizophrenia and D15S1360, the dinucleotide microsatellite marker previously identified in several association and linkage studies positively associated with schizophrenia. Iwata et al. (42) investigated 11 SNPs and three microsatellites, including D15S1360 and rs904952, in Chinese patients and controls and found no significant association between polymorphisms and schizophrenia. In addition, publication bias has to be taken into account. 


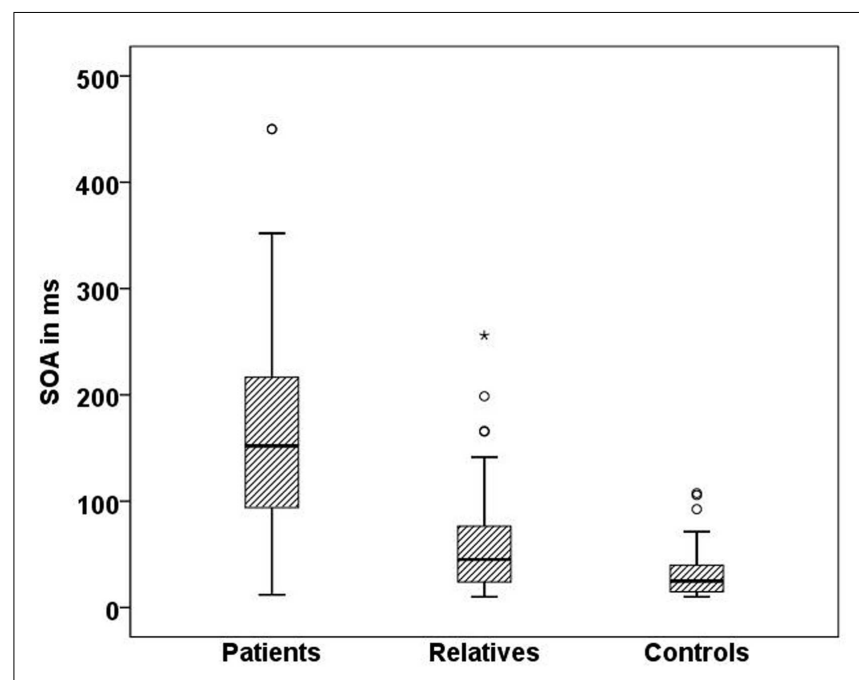

FIGURE 4 | Mean SOA in milliseconds for each Georgian group. Schizophrenic patients $(n=50)$ perform worse than healthy relatives $(n=57)$ and controls $(n=51), \mathrm{SD}=81.7, p<0.001$.

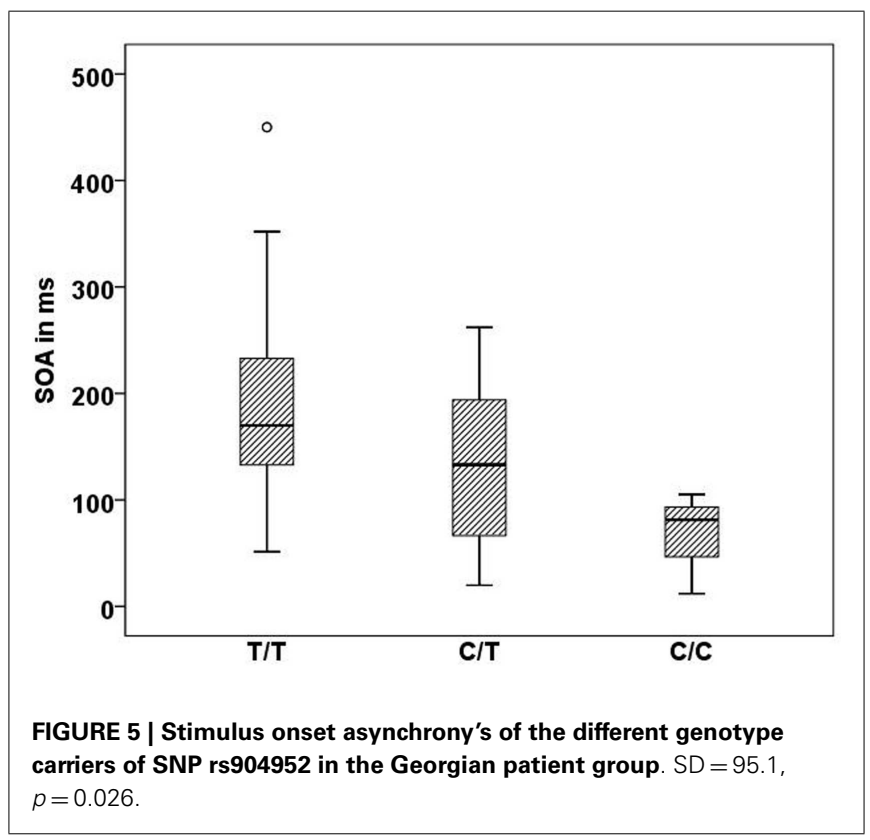

It is known for more than half century that visual information processing is impaired in schizophrenic patients $(25,26,30,31$, 56). Whereas performance deteriorates also in healthy observers, the deterioration is much more pronounced in schizophrenic patients (57-59). Visual masking deficits have been proposed for decades to be a vulnerability marker for schizophrenia (6064). Evidence comes from studies showing that also unaffected siblings of patients show masking deficits compared to controls (65-68), likewise adolescents with psychosis adolescents (69-72), and that masking deficits are rather constant for more than year in schizophrenic patients $(73,74)$. A particularly sensitive masking paradigm is the shine-through effect, revealing spatio-temporal information processing at the brink of human visual resolution in healthy human observers $(75,76)$ and schizophrenic patients (27-31). In a previous study, we have shown that the shinethrough paradigm is a particular sensitive VBM technique which outperforms classical cognitive tests such as the CPT and the WCST (VBM sensitivity: 87\%, specificity: 89\%) (27). Moreover, the shine-through masking paradigm meets the practicability and explicability criteria proposed by Turetsky et al. (77). It is easy and fast to apply, and independent of culture, education, and gender.

As in previous research (27), the present study also identified significant performance differences between patients, relatives, and controls in the Georgian sample. In addition, we found a robust association of SNP rs904952 with VBM, the same SNP that was also found to be associated with schizophrenia in the German sample. This finding supports the important role of the nicotinic system in the pathophysiology of schizophrenia and related clinical parameters such as VBM performance. It needs to be evaluated if drugs affecting the nicotinic system influence VBM.

In our study, the positive association between CHRNA7 and VBM was only found in patients but not in the healthy relatives as we may have expected it from a vulnerability marker. This result is likely due to the small sample size but may also be explained by additional genetic or non-genetic components not present in the relatives. With CHRNA7 we may have identified one important component in the pathophysiology of schizophrenia. However, other factors are certainly necessary. It is interesting, and very much at the heart of the endophenotype concept, that VBM deficits were significantly associated with mutations in the cholinergic system even though there was no significant association with the diagnosis of schizophrenia.

There are limitations with our study. None of the GWAS studies so far could confirm a single candidate gene for schizophrenia although statistical power of these studies is usually considerably larger than in conventional association studies $(78,79)$. Therefore, the association of CHRNA7 with schizophrenia needs to be carefully followed up. In addition, unknown confounding factors may lead to a hidden stratification bias. The significant SNP rs904952 is not in HWE in the German sample. This might be due to sampling procedures since inclusion criteria required only one generation of Central European descent prior to the participant. Particularly in Berlin with strong migration, this might have led to a partly inhomogeneous sample. Another limitation of our VBM study is the small sample size, although a significant effect with such a small sample size argues rather for the reliability of the findings. Still, the results on VBM need to be replicated in an independent and larger sample. In addition, studies are needed to investigate the expression of CHRNA7 transcripts in brains of schizophrenic patients to identify the specific risk domain in the gene. Goghari et al. found an association of backward masking deficits with the COMT Val158Met in schizophrenic patients (80). Hence, future research has to evaluate other promising candidate genes of schizophrenia and their common impact on VBM.

In summary we found a positive association between a polymorphism of the CHRNA7 gene and schizophrenia. In the smaller Georgian sample the same trend was observed. In line with prior studies, VBM with the shine-through masking paradigm showed 
profound deficits in schizophrenic patients and, to a lower extent, in their healthy first-degree relatives. In addition, we have shown that VBM has a genetic component that runs in parallel with the diagnosis of schizophrenia.

\section{ACKNOWLEDGMENTS}

Michael Herzog, Maya Roinishvili, and Eka Chkoina are members of the NCCR Synapsy of the Swiss National Science Foundation (SNF). Imke Puls and Michael Herzog are responsible for the study design. Andreas Brand and Eka Chkonia supervised the psychopathological assessment and evaluation. Maya Roinishvili

\section{REFERENCES}

1. Eisener A, Pato MT, Medeiros H, Carvalho C, Pato CN. Genetics of schizophrenia: recent advances. Psychopharmacol Bull (2007) 40:168-77.

2. O’Donovan MC, Craddock NJ, Owen MJ. Genetics of psychosis; insights from views across the genome. Hum Genet (2009) 126:3-12. doi:10.1007/s00439-009-0703-0

3. Schwab SG, Wildenauer DB. Update on key previously proposed candidate genes for schizophrenia. Curr Opin Psychiatry (2009) 22:147-53. doi:10.1097/YCO. 0b013e328325a598

4. Sun J, Jia P, Fanous AH, van den Oord E, Chen X, Riley BP, et al. Schizophrenia gene networks and pathways and their applications for novel candidate gene selection. PLoS One (2010) 5:e11351. doi:10.1371/ journal.pone.0011351

5. Sanders AR, Duan J, Levinson DF, Shi J, He D, Hou C, et al. No significant association of 14 candidate genes with schizophrenia in a large European ancestry sample: implications for psychiatric genetics. Am J Psychiatry (2008) 165: 497-506. doi:10.1176/appi.ajp. 2007.07101573

6. Freedman R, Hall M, Adler LE, Leonard S. Evidence in postmortem brain tissue for decreased numbers of hippocampal nicotinic receptors in schizophrenia. Biol Psychiatry (1995) 38:22-33. doi:10.1016/00063223(94)00252-X

7. Severance EG, Yolken RH. Novel alpha7 nicotinic receptor isoforms and deficient cholinergic transcription in schizophrenia. Genes Brain Behav (2008) 7:37-45. doi:10.1111/j.1601-183X.2007. 00323.x

8. Taly A, Corringer PJ, Guedin D, Lestage P, Changeux JP. Nicotinic receptors: allosteric transitions and therapeutic targets in the nervous system. Nat Rev Drug Discov (2009) 8:733-50. doi:10.1038/nrd2927
9. Leonard S, Gault J, Hopkins J, Logel J, Vianzon R, Short M, et al. Association of promoter variants in the alpha7 nicotinic acetylcholine receptor subunit gene with an inhibitory deficit found in schizophrenia. Arch Gen Psychiatry (2002) 59:1085-96. doi:10.1001/archpsyc. 59.12.1085

10. Stassen HH, Bridler R, Hagele S, Hergersberg $M$, Mehmann B, Schinzel A, et al. Schizophrenia and smoking: evidence for a common neurobiological basis? Am J Med Genet (2000) 96:173-7. doi:10.1002/(SICI)10968628(20000403)96:2<173::AIDAJMG10>3.0.CO;2-U

11. Stephens SH, Logel J, Barton A, Franks A, Schultz J, Short $\mathrm{M}$, et al. Association of the 5 '-upstream regulatory region of the alpha7 nicotinic acetylcholine receptor subunit gene (CHRNA7) with schizophrenia. Schizophr Res (2009) 109:102-12. doi:10.1016/j. schres.2008.12.017

12. Freedman R, Coon H, MylesWorsley M, Orr-Urtreger A, Olincy A, Davis A, et al. Linkage of a neurophysiological deficit in schizophrenia to a chromosome 15 locus. Proc Natl Acad Sci U S A (1997) 94:587-92. doi:10.1073/ pnas.94.2.587

13. Freedman R, Leonard S, Gault JM, Hopkins J, Cloninger CR, Kaufmann CA, et al. Linkage disequilibrium for schizophrenia at the chromosome 15q13-14 locus of the alpha7-nicotinic acetylcholine receptor subunit gene (CHRNA7). Am J Med Genet (2001) 105:20-2. doi:10.1002/1096-8628(20010108) 105:1<20::AID-AJMG1047>3.0. $\mathrm{CO} ; 2-\mathrm{C}$

14. Tsuang DW, Skol AD, Faraone SV, Bingham S, Young KA, Prabhudesai S, et al. Examination of genetic linkage of chromosome 15 to schizophrenia in a large Veterans Affairs Cooperative Study sample. Am J Med Genet (2001) 105:662-8. doi: 10.1002/ajmg.1550.abs

supervised the experimental data recording and analysis. George Bakanidze, Imke Puls, Werner Kitzrow, and Sarina Richter performed the genetic analysis, George Bakanidze, Andreas Brand, and Imke Puls performed the statistical analysis, and George Bakanidze wrote the first draft of the manuscript. All authors contributed to the writing of the manuscript and have approved the final version. Financial disclosures: Funding for this study was provided by the Volkswagen Foundation Grant I/83 401. The Volkswagen Foundation had no further role in the study design, collection, analysis and interpretation of data, writing of the report, and decision to submit the paper for publication.

15. Gault J, Hopkins J, Berger R, Drebing C, Logel J, Walton C, et al. Comparison of polymorphisms in the alpha7 nicotinic receptor gene and its partial duplication in schizophrenic and control subjects. Am J Med Genet B Neuropsychiat Genet (2003) 123B:39-49. doi:10. 1002/ajmg.b.20061

16. Consortium IS. Rare chromosomal deletions and duplications increase risk of schizophrenia. Nature (2008) 455:237-41. doi:10. 1038/nature07239

17. Itsara A, Cooper GM, Baker C, Girirajan S, Li J, Absher D, et al. Population analysis of large copy number variants and hotspots of human genetic disease. Am J Hum Genet (2009) 84:148-61. doi:10. 1016/j.ajhg.2008.12.014

18. Stefansson H, Rujescu D, Cichon S, Pietilainen OP, Ingason A, Steinberg $\mathrm{S}$, et al. Large recurrent microdeletions associated with schizophrenia. Nature (2008) 455:232-6. doi:10. 1038/nature07229

19. Breese CR, Lee MJ, Adams CE, Sullivan B, Logel J, Gillen KM, et al. Abnormal regulation of high affinity nicotinic receptors in subjects with schizophrenia. Neuropsychopharmacology (2000) 23:351-64. doi:10.1016/S0893133X(00)00121-4

20. Guan ZZ, Zhang X, Blennow K, Nordberg A. Decreased protein level of nicotinic receptor alpha7 subunit in the frontal cortex from schizophrenic brain. Neuroreport (1999) 10:1779-82. doi:10.1097/ 00001756-199906030-00028

21. Dalack GW, Healy DJ, MeadorWoodruff JH. Nicotine dependence in schizophrenia: clinical phenomena and laboratory findings. Am J Psychiatry (1998) 155:1490-501.

22. de Leon J, Dadvand M, Canuso C, White AO, Stanilla JK, Simpson GM. Schizophrenia and smoking: an epidemiological survey in a state hospital. Am J Psychiatry (1995) 152:453-5.
23. Lasser K, Boyd JW, Woolhandler S, Himmelstein DU, McCormick D, Bor DH. Smoking and mental illness: a population-based prevalence study. JAMA (2000) 284:2606-10. doi:10.1001/jama.284.20.2606

24. Leonard S, Bertrand D. Neuronal nicotinic receptors: from structure to function. Nicotine Tob Res (2001) 3:203-23. doi:10.1080/ 14622200110050213

25. Dawson ME, Schell AM, Hazlett EA, Nuechterlein KH, Filion DL. On the clinical and cognitive meaning of impaired sensorimotor gating in schizophrenia. Psychiatry Res (2000) 96:187-97. doi:10.1016/ S0165-1781(00)00208-0

26. Perry W, Minassian A, Feifel D, Braff DL. Sensorimotor gating deficits in bipolar disorder patients with acute psychotic mania. Biol Psychiatry (2001) 50:418-24. doi:10.1016/ S0006-3223(01)01184-2

27. Chkonia E, Roinishvili M, Makhatadze N, Tsverava L, Stroux A, Neumann K, et al. The shinethrough masking paradigm is a potential endophenotype of schizophrenia. PLoS One (2010) 5:e14268. doi:10.1371/journal.pone.0014268

28. Grimsen C, Brand A, Fahle M. No evidence for prolonged visible persistence in patients with schizophrenia. PLoS One (2013) 8(3):e58940. doi:10.1371/journal.pone.0058940.

29. Herzog MH, Kopmann S, Brand A. Intact figure-ground segmentation in schizophrenia. Psychiatry Res (2004) 129:55-63. doi:10.1016/ j.psychres.2004.06.008

30. Roinishvili M, Chkonia E, Brand A, Herzog MH. Contextual suppression and protection in schizophrenic patients. Eur Arch Psychiatry Clin Neurosci (2008) 258:210-6. doi:10.1007/s00406007-0780-9

31. Schutze C, Bongard I, Marbach S, Brand A, Herzog MH. Collinear contextual suppression in schizophrenic patients. Psychiatry Res (2007) 150:237-43. doi:10.1016/j. psychres.2006.03.021 
32. Herzog MH, Roinishvili M, Chkonia E, Brand A. Schizophrenia and visual backward masking: a general deficit of target enhancement. Front Psychol (2013) 4:254. doi:10.3389/ fpsyg.2013.00254

33. Adler LE, Hoffer LD, Wiser A, Freedman R. Normalization of auditory physiology by cigarette smoking in schizophrenic patients. Am J Psychiatry (1993) 150:1856-61.

34. Brinkmeyer J, Mobascher A, Musso F, Schmitz M, Frommann I, Grunder G, et al. P50 sensory gating and smoking in the general population. Addict Biol (2011) 16:485-98. doi:10.1111/j.1369-1600.2010. 00302.x

35. Chen XS, Li CB, Smith RC, Xiao ZP, Wang JJ. Differential sensory gating functions between smokers and non-smokers among drug-naive first episode schizophrenic patients. Psychiatry Res (2011) 188(3):327-33. doi:10.1016/ j.psychres.2010.12.009

36. Millar A, Smith D, Choueiry J, Fisher $\mathrm{D}$, Albert $\mathrm{P}$, Knott $\mathrm{V}$. The moderating role of the dopamine transporter 1 gene on P50 sensory gating and its modulation by nicotine. Neuroscience (2011) 180:148-56. doi:10. 1016/j.neuroscience.2011.02.008

37. Raux G, Bonnet-Brilhault F, Louchart S, Houy E, Gantier R, Levillain $\mathrm{D}$, et al. The -2 bp deletion in exon 6 of the 'alpha 7-like' nicotinic receptor subunit gene is a risk factor for the P50 sensory gating deficit. Mol Psychiatry (2002) 7:1006-11. doi:10.1038/sj.mp.4001140

38. Olincy A, Harris JG, Johnson LL, Pender V, Kongs S, Allensworth D, et al. Proof-of-concept trial of an alpha7 nicotinic agonist in schizophrenia. Arch Gen Psychiatry (2006) 63:630-8. doi:10.1001/archpsyc.63. 6.630

39. Espeseth T, Endestad T, Rootwelt H, Reinvang I. Nicotine receptor gene CHRNA4 modulates early eventrelated potentials in auditory and visual oddball target detection tasks. Neuroscience (2007) 147:974-85. doi:10.1016/j.neuroscience.2007. 04.027

40. Andreasen N. Scale for Assessment of the Negative Symptoms (SANS). Iowa: University of Iowa (1983).

41. Andreasen N. Scale of the Assessment of Positive Symptoms (SAPS). Iowa: University of Iowa (1984).

42. Iwata Y, Nakajima M, Yamada K, Nakamura K, Sekine Y, Tsuchiya $\mathrm{KJ}$, et al. Linkage disequilibrium analysis of the CHRNA7 gene and its partially duplicated region in schizophrenia. Neurosci Res
(2007) 57:194-202. doi:10.1016/j. neures.2006.10.002

43. Nuechterlein KH, Dawson ME, Green MF. Information-processing abnormalities as neuropsychological vulnerability indicators for schizophrenia. Acta Psychiatr Scand (1994) 384:71-9. doi:10.1111/j. 1600-0447.1994.tb05894.x

44. Taylor MM, Forbes SM, Creelman CD. PEST reduces bias in forced choice psychophysics. J Acoust Soc Am (1983) 74:1367-74. doi:10. $1121 / 1.390161$

45. Herzog $\mathrm{MH}$, Koch C, Fahle M. Shine-through: temporal aspects. Vision Res (2001) 41:2337-46. doi: 10.1016/S0042-6989(01)00123-7

46. Faul F, Erdfelder E, Lang AG, Buchner A. $G^{\star}$ Power 3: a flexible statistical power analysis program for the social, behavioral, and biomedical sciences. Behav Res Methods (2007) 39:175-91. doi:10.3758/ BF03193146

47. Barrett JC, Fry B, Maller J, Daly MJ. Haploview: analysis and visualization of LD and haplotype maps. Bioinformatics (2005) 21:263-5. doi:10.1093/bioinformatics/bth457

48. Wigginton JE, Cutler DJ, Abecasis GR. A note on exact tests of Hardy-Weinberg equilibrium. Am J Hum Genet (2005) 76:887-93. doi: $10.1086 / 429864$

49. Gault J, Robinson M, Berger R, Drebing C, Logel J, Hopkins J, et al. Genomic organization and partial duplication of the human alpha7 neuronal nicotinic acetylcholine receptor gene (CHRNA7). Genomics (1998) 52:173-85. doi:10. 1006/geno.1998.5363

50. De Luca V, Wang H, Squassina A, Wong GW, Yeomans J, Kennedy JL. Linkage of M5 muscarinic and alpha7-nicotinic receptor genes on 15 q13 to schizophrenia. Neuropsychobiology (2004) 50:124-7. doi:10. 1159/000079102

51. Freedman R, Leonard S, Waldo M, Gault J, Olincy A, Adler LE. Characterization of allelic variants at chromosome $15 \mathrm{q} 14$ in schizophrenia. Genes Brain Behav (2006) 5(Suppl 1):14-22. doi:10.1111/j.1601-183X. 2006.00190.x

52. Riley BP, Makoff A, Mogudi-Carter $\mathrm{M}$, Jenkins T, Williamson R, Collier $\mathrm{D}$, et al. Haplotype transmission disequilibrium and evidence for linkage of the CHRNA7 gene region to schizophrenia in Southern African Bantu families. Am Med Genet (2000) 96:196-201. doi:10.1002/(SICI)10968628(20000403)96:2<196::AIDAJMG15>3.0.CO;2-4
53. Xu J, Pato MT, Torre CD, Medeiros $\mathrm{H}$, Carvalho C, Basile VS, et al. Evidence for linkage disequilibrium between the alpha 7-nicotinic receptor gene (CHRNA7) locus and schizophrenia in Azorean families. Am J Med Genet (2001) 105:669-74. doi:10.1002/ajmg.1549

54. Stephens SH, Franks A, Berger R, Palionyte M, Fingerlin TE, Wagner $\mathrm{B}$, et al. Multiple genes in the 15q13q14 chromosomal region are associated with schizophrenia. Psychiat Genet (2012) 22:1-14. doi:10.1097/ YPG.0b013e32834c0c33

55. Fan JB, Ma J, Li XW, Zhang CS, Sun WW, He G, et al. Populationbased and family-based association studies of an (AC)n dinucleotide repeat in alpha-7 nicotinic receptor subunit gene and schizophrenia. Schizophr Res (2006) 84 222-7. doi:10.1016/j.schres.2006. 02.012

56. Cullum CM, Harris JG, Waldo MC, Smernoff E, Madison A, Nagamoto HT, et al. Neurophysiological and neuropsychological evidence for attentional dysfunction in schizophrenia. Schizophr Res (1993) 10:131-41. doi:10.1016/ 0920-9964(93)90048-N

57. Butler PD, DeSanti LA, Maddox J, Harkavy-Friedman JM, Amador XF, Goetz RR, et al. Visual backwardmasking deficits in schizophrenia: relationship to visual pathway function and symptomatology. Schizophr Res (2003) 59:199-209. doi:10. 1016/S0920-9964(01)00341-3

58. Cadenhead KS, Geyer MA, Butler RW, Perry W, Sprock J, Braff DL. Information processing deficits of schizophrenia patients: relationship to clinical ratings, gender and medication status. Schizophr Res (1997) 28:51-62. doi:10.1016/ S0920-9964(97)00085-6

59. Koelkebeck K, Ohrmann P, Hetzel G, Arolt V, Suslow T. Visual backward masking: deficits in locating targets are specific to schizophrenia and not related to intellectual decline. Schizophr Res (2005) 78:261-8. doi:10.1016/j.schres.2005.01.017

60. Green MF, Nuechterlein KH, Mintz J. Backward masking in schizophrenia and mania. II. Specifying the visual channels. Arch Gen Psychiatry (1994) 51:945-51. doi:10.1001/ archpsyc.1994.03950120011003

61. Green MF, Nuechterlein KH, Mintz J. Backward masking in schizophrenia and mania. I. Specifying a mechanism. Arch Gen Psychiatry (1994) 51:939-44. doi:10.1001/ archpsyc.1994.03950120011003
62. Saccuzzo DP, Hirt M, Spencer TJ. Backward masking as a measure of attention in schizophrenia. J Abnorm Psychol (1974) 83:512-22. doi:10.1037/h0037072

63. Saccuzzo DS, Cadenhead KS, Braff DL. Backward versus forward visual masking deficits in schizophrenic patients: centrally, not peripherally, mediated? Am J Psychiatry (1996) 153:1564-70.

64. Slaghuis WL, Curran CE. Spatial frequency masking in positive- and negative-symptom schizophrenia. J Abnorm Psychol (1999) 108:42-50. doi:10.1037/0021-843X.108.1.42

65. Bedwell JS, Brown JM, Miller LS. The magnocellular visual system and schizophrenia: what can the color red tell us? Schizophr Res (2003) 63:273-84. doi:10.1016/ S0920-9964(02)00356-0

66. Green MF, Nuechterlein KH, Breitmeyer B. Backward masking performance in unaffected siblings of schizophrenic patients. Evidence for a vulnerability indicator. Arch Gen Psychiatry (1997) 54:465-72. doi:10.1001/archpsyc. 1997.01830170091012

67. Green MF, Nuechterlein $\mathrm{KH}$ Breitmeyer B, Mintz J. Forward and backward visual masking in unaffected siblings of schizophrenic patients. Biol Psychiatry (2006) 59: 446-51. doi:10.1016/j.biopsych. 2005.06.035

68. Keri S, Kelemen O, Benedek G, Janka Z. Different trait markers for schizophrenia and bipolar disorder: a neurocognitive approach. Psychol Med (2001) 31:915-22. doi:10. 1017/S0033291701004068

69. Lieb K, Denz E, Hess R, Schuttler R, Kornhuber HH, Schreiber H. Preattentive information processing as measured by backward masking and texton detection tasks in adolescents at high genetic risk for schizophrenia. Schizophr Res (1996) 21:171-82. doi:10.1016/ 0920-9964(96)00025-4

70. Rund BR, Oie M, Sundet K. Backward-masking deficit in adolescents with schizophrenic disorders or attention deficit hyperactivity disorder. Am J Psychiatry (1996) 153:1154-7.

71. Saccuzzo DP, Schubert DL. Backward masking as a measure of slow processing in schizophrenia spectrum disorders. J Abnorm Psychol (1981) 90:305-12. doi:10.1037/ 0021-843X.90.4.305

72. Ueland $\mathrm{T}$, Oie $\mathrm{M}$, Inge Landro $\mathrm{N}$, Rund BR. Cognitive functioning in adolescents with schizophrenia spectrum disorders. Psychiatry Res 
(2004) 126:229-39. doi:10.1016/j. psychres.2004.02.014

73. Lee J, Nuechterlein KH, Subotnik KL, Sugar CA, Ventura J, GretchenDoorly D, et al. Stability of visual masking performance in recentonset schizophrenia: an 18-month longitudinal study. Schizophr Res (2008) 103:266-74. doi:10.1016/j. schres.2008.03.005

74. Rund BR, Landro NI, Orbeck AL. Stability in backward masking performance in schizophrenics, affectively disturbed patients, and normal subjects. J Nerv Ment Dis (1993) 181: 233-7. doi:10.1097/00005053199304000-00004

75. Herzog MH, Fahle M. Effects of grouping in contextual modulation. Nature (2002) 415:433-6. doi:10. $1038 / 415433 a$

76. Herzog MH, Koch C. Seeing properties of an invisible object: feature inheritance and shinethrough. Proc Natl Acad Sci U S A (2001) 98:4271-5. doi:10.1073/ pnas.071047498

77. Turetsky BI, Calkins ME, Light GA, Olincy A, Radant AD, Swerdlow NR. Neurophysiological endophenotypes of schizophrenia: the viability of selected candidate measures. Schizophr Bull (2007) 33:69-94. doi:10.1093/schbul/sbl060

78. Collins AL, Kim Y, Sklar P, O'Donovan MC, Sullivan PF. Hypothesis-driven candidate genes for schizophrenia compared to genome-wide association results. Psychol Med (2011) 42(3): 607-16. doi:10.1017/ S0033291711001607

79. Ripke S, Sanders AR, Kendler KS, Levinson DF, Sklar P, Holmans PA, et al. Genome-wide association study identifies five new schizophrenia loci. Nat Genet (2011) 43:969-76. doi:10.1038/ng. 940

80. Goghari VM, Sponheim SR Divergent backward masking performance in schizophrenia and bipolar disorder: association with COMT. Am JMed Genet B Neuropsychiatr Genet (2008) 147B:223-7. doi:10.1002/ajmg.b.30583

Conflict of Interest Statement: The authors declare that the research was conducted in the absence of any commercial or financial relationships that could be construed as a potential conflict of interest.

Received: 28 July 2013; accepted: 01 October 2013; published online: 22 October 2013.

Citation: Bakanidze G, Roinishvili M, Chkonia E, Kitzrow W, Richter S,
Neumann K, Herzog MH, Brand A and Puls I (2013) Association of the nicotinic receptor $\alpha 7$ subunit gene (CHRNA7) with schizophrenia and visual backward masking. Front. Psychiatry 4:133. doi: 10.3389/fpsyt.2013.00133

This article was submitted to Molecular Psychiatry, a section of the journal Frontiers in Psychiatry.

Copyright (C) 2013 Bakanidze, Roinishvili, Chkonia, Kitzrow, Richter, Neumann, Herzog, Brand and Puls. This is an open-access article distributed under the terms of the Creative Commons Attribution License (CC BY).

The use, distribution or reproduction in other forums is permitted, provided the original author(s) or licensor are credited and that the original publication in this journal is cited, in accordance with accepted academic practice. No use, distribution or reproduction is permitted which does not comply with these terms. 